\title{
O PROGRAMA DE TUTORIA NO ENSINO NÃO PRESENCIAL EMERGENCIAL DE GRADUAÇÃO NA UNIVERSIDADE FEDERAL DE SÃO CARLOS
}

Adriana P. F. Palhares ${ }^{1}$ - apf@ufscar.br

Alex C. Rezende ${ }^{2}$ - alexcr@ufscar.br

Claudia B. G. Moussa ${ }^{3}$ - gentile@dm.ufscar.br

Flávio Y. Watanabe ${ }^{4}$ - fywatanabe@ufscar.br

Universidade Federal de São Carlos - UFSCar

Departamento de Engenharia Química ${ }^{1}$, Departamento de Matemática ${ }^{2}$,

Pró-Reitoria de Graduação ${ }^{3}$, Departamento de Engenharia Mecânica ${ }^{4}$

Rod. Washington Luís, km 235 - SP-310 - São Carlos

CEP 13565-905 - São Carlos - São Paulo

Resumo: O elevado índice de retenção em atividades curriculares iniciais nos cursos de graduação é uma das causas de evasão de estudantes e motivo de preocupação das Instituições de Ensino Superior (IES). Os estudantes ingressantes precisam se adaptar rapidamente às novas rotinas acadêmicas e a um novo modelo de ensino-aprendizagem que exige mais autonomia e disciplina nos estudos. Buscando ofertar apoio acadêmico aos estudantes ingressantes, a Universidade Federal de São Carlos (UFSCar) estruturou em 2017 um programa de tutoria no qual estudantes tutores auxiliam os estudantes atendidos a desenvolverem uma rotina apropriada de estudos, visando uma possível melhoria no desempenho ao longo da graduação. $O$ crescimento no número de atendimentos ao longo dos anos e os relatos dos estudantes atendidos indicam que a tutoria tem contribuído globalmente em sua formação. Entretanto, em 2020, como reflexo da pandemia de COVID-19, todo o ensino de graduação passou ao formato não presencial e a tutoria teve de se adaptar a esse novo contexto. Utilizando Tecnologias Digitais de Informação e Comunicação (TDICs) disponíveis aos tutores e estudantes atendidos, e também certa dose de criatividade, foram adotadas estratégias remotas que preservassem os principios norteadores do programa que visam incentivar os estudantes a criarem uma rotina de estudos e a buscarem formas mais eficientes de estudo e aprendizagem. Neste trabalho, é relatado o processo de criação e implantação do programa de tutoria da UFSCar, bem como sua adequação à modalidade remota de atendimento.

Palavras-chave: Ensino Remoto Emergencial. EaD. TDIC. Evasão estudantil.

\section{INTRODUÇÃO}

Os elevados índices de retenção e evasão no ensino superior, bem como os motivos que levam a estas situações, são questões que preocupam as Instituições de Ensino Superior (IES). Os dados divulgados anualmente pelo Instituto Nacional de Estudos e Pesquisas Educacionais Anísio Teixeira (Inep) sobre o Censo da Educação Superior têm mostrado números crescentes de novos ingressos e de total de matrículas no ensino superior, mas esta evolução é acompanhada de um crescimento discreto do número de estudantes que concluíram os cursos nos quais ingressaram inicialmente. Esse descompasso pode ser atribuído aos elevados índices de evasão, evidenciados por meio do acompanhamento por 5 anos da trajetória de estudantes 
(C) COBENCE

"Os desafios para formar hoje o engenheiro do amanhã"

ingressantes em 2010, resultando em uma taxa de desistência de $49 \%$ no conjunto geral de cursos superiores, ou de 52,7\% na rede privada e de 42,6\% na rede pública (INEP, 2016).

Seguindo outra estratégia de cálculo da taxa de evasão, o problema foi objeto de estudo realizado por Andreto (2015) que analisou dados dos 57 cursos de presenciais de graduação da Universidade Federal de São Carlos (UFSCar) e considerou o conjunto de ingressantes no período de 2008 a 2012, via vestibular ou Sistema de Seleção Unificada (SiSU). Neste período, de um total de 11.555 estudantes ingressantes, 2.961 evadiram de seu curso de ingresso até o $5^{\circ}$ semestre, refletindo em uma taxa de evasão total geral próxima de $26 \%$.

Segundo Lobo (2012), múltiplos fatores levam ao fenômeno de evasão, tais como: dificuldades de adaptação à vida acadêmica e ao processo de ensino-aprendizagem mais contínuo e autônomo; falta de maturidade; formação básica deficiente; falta de conhecimento sobre o curso escolhido; decepção com a pouca motivação e atenção dos professores; e até o alto investimento financeiro necessário no caso de instituições privadas.

Para enfrentar estes problemas, as IES têm atuado em diferentes frentes, implementando ações que buscam reduzir os índices de retenção e possível evasão, especialmente dos estudantes ingressantes. Na Universidade Federal de Viçosa (UFV) foi criado o Programa de Tutoria nas Ciências Básicas - PAB, no qual os estudantes ingressantes, dependendo dos resultados apresentados no processo seletivo, podem ser encaminhados ao atendimento da tutoria ou para disciplinas de revisão de conhecimentos básicos (PASSOS et al., 2001a,b).

$\mathrm{Na}$ UFSCar, um histórico de iniciativas institucionais é apresentado por Moussa et al. (2019). Tais iniciativas são ligadas ao apoio aos estudantes na modalidade de tutoria, desde 2005, e que culminaram na criação do "Programa de Apoio Acadêmico ao Estudante de Graduação" (PAAEG), em 2017, que congrega iniciativas diversificadas, incluindo um programa de tutoria no qual atua uma equipe de gestores, professores supervisores e estudantes tutores que atuam de forma presencial nos quatro campi da instituição e com foco principal nas atividades curriculares iniciais com índices elevados de retenção.

Entretanto, em março de 2020, o mundo sofreu uma transformação inusitada com a classificação pela Organização Mundial da Saúde (OMS) do surto de COVID-19 - causado pelo Novo Coronavírus - SARS Cov 2 - como uma pandemia global. A maior parte dos países adotou protocolos rigorosos de saúde pública e ações que promoviam o distanciamento social, visando o controle da propagação da pandemia. Instituições de ensino tiveram de suspender praticamente todas as atividades presenciais e a adotar soluções diversificadas de trabalho usando Tecnologias Digitais de Informação e Comunicação (TDIC), como os serviços de comunicação virtual e coletiva por meio de áudio e vídeo e os Ambientes Virtuais de Aprendizagem (AVA).

$\mathrm{Na}$ UFSCar, novas estratégias foram adotadas para viabilizar o ensino de graduação e o programa de tutoria para o apoio aos estudantes inscritos em atividades curriculares ofertadas remotamente pela instituição. Esse processo de mudança rápida a um novo formato de ensinoaprendizagem não é trivial e gera dúvidas, desânimo, conflitos e insegurança, mas uma parcela significativa de professores buscou se capacitar para o ensino remoto, por meio de iniciativas institucionais remotas de formação, seja em uso de TDICs ou de estratégias de ensino, aprendizagem e avaliação. Isotani (ICMC, 2020) enxerga este cenário global como uma oportunidade de transformação digital e cultural no ensino, unindo estratégias pedagógicas como o ensino híbrido e metodologias ativas com tecnologias educacionais, potencializando as capacidades de aprendizagem do aluno e de inovação do professor.

Nesse contexto, o presente trabalho apresenta um relato do processo de criação, implantação e adequação à modalidade remota do programa de tutoria PAAEG, baseado no histórico de ações da UFSCar no processo de elaboração e implementação de um plano de atividades voltadas ao ensino de graduação de forma não presencial e emergencial. 


\section{A TUTORIA PAAEG}

A tutoria PAAEG encontra-se em seu quarto ano de funcionamento nos quatro campi da UFSCar e conta atualmente com cerca de 90 estudantes tutores atendendo atividades curriculares das áreas de matemática, física, química, bioquímica, anatomia, fisiologia e escrita acadêmica, assim como outras mais específicas com elevados índices de retenção, concentradas principalmente nos semestres iniciais na maioria dos cursos da UFSCar.

Anualmente, é divulgado um edital que explicita as diretrizes gerais do programa e abre a inscrição aos estudantes candidatos à tutoria. A equipe de professores supervisores ou coordenadores de área seleciona estudantes para o programa, orienta os tutores em relação aos conteúdos abordados e elucida eventuais dúvidas. Cada estudante tutor recebe 10 meses de bolsa com valor compatível com o de Iniciação Científica e Tecnológica, visando valorizar a vocação para a atividade de ensino. Os tutores devem dedicar $12 \mathrm{~h}$ à tutoria PAAEG, sendo $6 \mathrm{~h}$ de atendimentos e $6 \mathrm{~h}$ de preparação. Eles são responsáveis pelo atendimento e pelo controle de frequência dos estudantes que buscam o atendimento dos diferentes serviços ofertados pela tutoria, bem como por emitir relatórios semestrais.

Moussa et al. (2019) apresentam em seu trabalho que um dos aspectos mais importantes da tutoria PAAEG é a atuação de forma diferenciada da monitoria tradicional, pois o objetivo principal da tutoria é auxiliar os estudantes atendidos a desenvolverem uma rotina apropriada de trabalho e incentivá-los a buscar processos de aprendizagem com mais autonomia, com vistas a uma melhoria no desempenho acadêmico não apenas ao longo do período em que estão sendo atendidos pelos tutores, mas ao longo de toda sua graduação. Os autores defendem que o contato com uma forma eficiente e prazerosa de estudos logo no ingresso da graduação pode fazer toda a diferença na vida acadêmica dos estudantes e culminar em profissionais mais bem formados, inclusive.

Neste sentido, é imperativo também que tutores sejam selecionados e capacitados para a atividade, e estejam aptos a receberem os estudantes logo no início do semestre letivo, evitando que um início tardio da tutoria, quando os processos de avaliação das atividades curriculares e a evasão já em curso, seja determinante para seu fracasso. E, buscando-se eliminar os obstáculos, os autores acreditam que a definição do local onde essas atividades serão desenvolvidas favorece o envolvimento dos estudantes, uma vez que, estando concentrados em um único local, todos sabem aonde devem se dirigir para buscar auxílio.

Os eventos de capacitação de tutores constituem uma etapa crucial do programa, buscando conscientizar os próprios estudantes tutores sobre a forma de atuação. Esses eventos de capacitação de tutores são organizados antes do início de cada período letivo, com duração média de dois dias, quando são proferidas palestras, dinâmicas de grupo e organizadas oficinas e rodas de conversa sobre temas correlacionados às temáticas de organização dos estudos, aprendizagem significativa, dificuldades acadêmicas, empatia e saúde mental, dentre outros. Também são planejadas estratégias de divulgação da tutoria e os estudantes tutores compartilham com o grupo suas expectativas, experiências, dificuldades e resultados.

Desde sua criação em 2017, a tutoria PAAEG ofertou três diferentes modalidades de atendimento:

- Tutoria de acompanhamento - o tutor se reúne semanalmente com um grupo fixo de estudantes previamente inscritos (cerca de 6 a 8 estudantes), ao longo de duas horas, acompanhando seus estudos em uma atividade curricular específica; o grupo fixo permite ao tutor um planejamento prévio da próxima sessão de estudos; a tutoria de acompanhamento é o grande foco da tutoria PAAEG; 
- Tutoria livre - o tutor recebe qualquer estudante para uma sessão assistida de duas horas de estudos de forma similar à monitoria, mas mantendo o diferencial de propor que o aluno atendido estude e busque soluções para suas dúvidas de forma ativa;

- Tutoria de nivelamento - os tutores fazem breves exposições sobre tópicos básicos do ensino fundamental e médio e propõem exercícios aos estudantes.

Os gráficos da Figura 1a mostram a evolução dos números globais de tutores PAAEG por campus e os da Figura 1b os números globais de atendimentos das diferentes modalidades de tutoria, de 2017 a 2019. A tutoria de nivelamento foi descontinuada já em 2017 devido à baixa adesão, cujas causas não foram investigadas a fundo, mas acredita-se que seu formato e denominação mostraram-se inadequados e pouco atrativos para o estudante ingressante.

Figura 1 - Número de tutores e atendimento da tutoria PAAEG

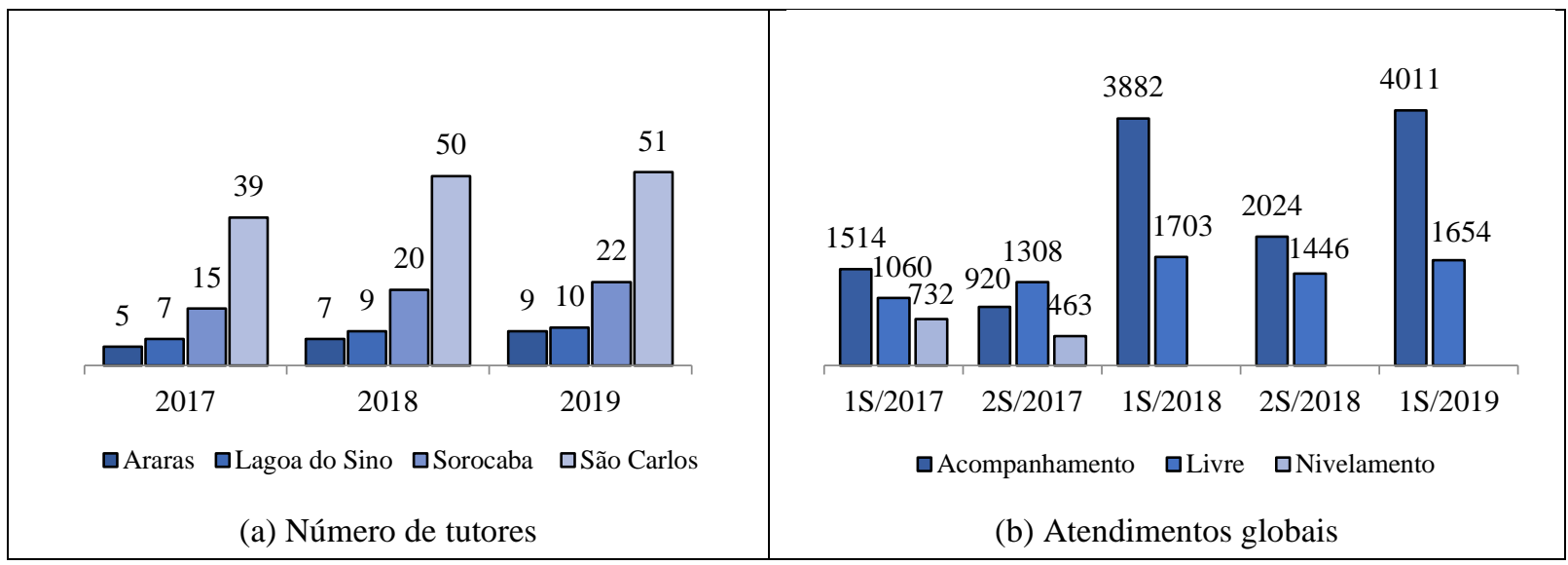

Legenda: $1 \mathrm{~S}-1^{\circ}$ semestre letivo; $2 \mathrm{~S}-2^{\circ}$ semestre letivo

Fonte: Moussa et al. (2019)

Ao final de cada semestre, tutores e estudantes atendidos respondem a questionários online sobre diferentes aspectos da tutoria e os resultados indicam que o programa trouxe benefícios a todos os envolvidos, seja na melhoria da rotina de estudos e no desempenho acadêmico dos estudantes, ou no despertar de vocações para a docência e o desenvolvimento de novas competências pelos tutores. No ano de 2020, em função da pandemia de COVID-19, as atividades do programa de tutoria foram suspensas após o cumprimento das etapas de lançamento de edital, seleção e capacitação dos tutores.

\section{O ENSINO REMOTO EMERGENCIAL}

"Ensino Remoto Emergencial" (ERE) é a denominação adotada para a modalidade de ensino neste período de pandemia de COVID-19, com o objetivo de adaptar o ensino presencial para a modalidade remota. Inicialmente, essa modalidade de ensino foi tratada como ensino on-line ou Educação a Distância (EaD) mediada por TDIC, entretanto, Hodges et al. (2020) defendem que as propostas bem planejadas de EaD são significativamente distintas dos cursos oferecidos remotamente em resposta a uma crise, como ocorre com a pandemia de COVID-19 e que o termo "Ensino Remoto Emergencial" é mais adequado à modalidade de ensino promovida pelos professores ao improvisar soluções rápidas sob circunstâncias não ideais. Isso fica evidente ao se comparar planejamento, capacitação docente, assessoria técnica e pedagógica, apoio tutorial e implantação da EaD com o ERE.

Embora o conceito de ensino emergencial possa ser novo para a maioria da população, a "Educação em Emergências" é uma triste realidade que afeta milhões de estudantes ao redor 
do mundo e refere-se à educação para populações afetadas por situações imprevistas, como conflitos armados ou desastres naturais, conforme explicitado por Sinclair (2001). Segundo Burde et al. (2017), quase um quarto da população mundial, cerca de 2 bilhões de pessoas, vive em países afetados por conflitos ou violência extrema e outros milhões são afetados anualmente por desastres relacionados ao clima e terremotos. Sinclair (2007) relata que, nestas emergências, agências da Organização das Nações Unidas (ONU) e organizações não governamentais $(\mathrm{ONG})$ internacionais e locais apoiam ações educacionais em países carentes de serviços estatais, com o objetivo de proteger as crianças de danos e promover o desenvolvimento cognitivo, emocional e social.

A pandemia de COVID-19 trouxe a necessidade de se adotar o ensino emergencial em escala mundial e evidenciou as desigualdades socioeconômicas locais e globais. Nas instituições públicas, principalmente, uma parcela significativa de estudantes não dispõe de dispositivos tecnológicos e de conexão de internet adequados para acompanhar o ensino remoto mediado por TDIC, e até mesmo apresenta certa dificuldade em se adaptar a esta modalidade de estudo e aprendizagem, uma vez que sua experiência anterior foi baseada principalmente no ensino presencial.

Soma-se a isso o fato das instituições de ensino nem sempre possuírem sistemas de informação e comunicação adequados ao uso no ensino remoto com o acesso simultâneo de um número elevado de usuários. Outra dificuldade é enfrentada pelos educadores cuja maioria não possui experiência e conhecimento sobre a utilização dessas tecnologias digitais no ensino não presencial, necessitando se capacitar rapidamente e remotamente para garantir uma qualidade mínima de ensino.

Na UFSCar, várias iniciativas foram adotadas para um planejamento adequado da oferta de atividades acadêmicas em uma modalidade de ensino não presencial. Primeiramente, o primeiro período letivo iniciado pouco antes da interrupção das atividades acadêmicas presenciais foi suspenso e, posteriormente, cancelado, com exceção dos cursos que apresentam estrutura pedagógica anual. Posteriormente, foi instituído um período letivo suplementar de 8 semanas para a oferta exclusiva de disciplinas de monografia ou trabalho de conclusão de curso, ou de atividades de extensão denominadas Atividades Curriculares de Integração entre Ensino, Pesquisa e Extensão (ACIEPEs), todas por meios digitais e remotos.

Um exemplo significativo de ACIEPE foi a denominada "Matemática Elementar", relatada por Dalbelo e Rezende (2020). Inicialmente planejada para o atendimento de estudantes ingressantes nos cursos de Matemática, recebeu inscrições de estudantes de outros cursos e do Ensino Médio, totalizando cerca de 800 inscrições. A iniciativa contou com a participação de vários professores, pós-graduandos e tutores, e envolveu videoaulas, materiais de leitura, fóruns de dúvidas e atividades avaliativas, tudo mediado por meio de um Ambiente Virtual de Aprendizagem (AVA). Os estudantes relataram problemas como a falta de recursos digitais e espaços adequados, dificuldade de concentração e necessidade de se dedicar ao cuidado de familiares que culminaram em desistências. Entretanto, a experiência relatada mostrou-se efetiva no ensino de conteúdos elementares da matemática no formato não presencial e pode ser usada como referência para a implantação de iniciativas similares.

A Pró-Reitoria de Graduação (ProGrad) da UFSCar realizou também duas consultas por meio de formulários on-line, sendo uma direcionada aos estudantes e outra aos professores da instituição. O objetivo dessas consultas foi fazer um diagnóstico sobre as principais dificuldades e possibilidades de atuação no formato remoto de ensino.

Na UFSCar são 65 cursos presenciais de graduação ofertados em 4 campi e com cerca de 14.000 estudantes ativos. Cerca de $88 \%$ dos estudantes ativos responderam a consulta e uma síntese das informações coletadas é apresentada no Quadro 1. 
Quadro 1 - Resultados da consulta aos discentes sobre suas condições de acesso ao ensino por meios virtuais

\begin{tabular}{|c|c|c|c|c|c|c|}
\hline - Isolamento social & \multicolumn{2}{|l|}{$39,9 \% \operatorname{sim}$} & \multicolumn{2}{|c|}{$57,8 \%$ parcial } & \multicolumn{2}{|r|}{$2,3 \%$ não } \\
\hline $\begin{array}{l}\text { - Impactos do } \\
\text { isolamento social }\end{array}$ & $21,3 \%$ nenhum & \multicolumn{2}{|c|}{$41,3 \%$ financeiro } & \multicolumn{2}{|c|}{$59,3 \%$ emocional } & $4,6 \%$ outros \\
\hline - Acesso à internet & \multicolumn{2}{|l|}{$93,7 \%$ ilimitado } & \multicolumn{2}{|c|}{$3,4 \%$ limitado } & \multicolumn{2}{|c|}{ 2,9\% precário/impeditivo } \\
\hline $\begin{array}{l}\text { Acesso a dispositivos } \\
\text { ou equipamentos }\end{array}$ & $\begin{array}{c}77,7 \% \text { computador } \\
\text { próprio }\end{array}$ & \multicolumn{2}{|c|}{$\begin{array}{l}9,3 \% \text { computador } \\
\text { compartilhado }\end{array}$} & \multicolumn{2}{|c|}{$\begin{array}{l}6,6 \% \text { tablet } \text { ou } \\
\text { smartphone }\end{array}$} & $\begin{array}{l}6,3 \% \text { sem acesso } \\
\text { ou acesso limitado }\end{array}$ \\
\hline $\begin{array}{l}\text { - Condições gerais para } \\
\text { o ensino remoto }\end{array}$ & \multicolumn{2}{|c|}{$\begin{array}{l}84 \% \text { em condições e com } \\
\text { internet/equipamento }\end{array}$} & \multicolumn{2}{|c|}{$\begin{array}{l}9 \% \text { sem condições, mas } \\
\text { com internet/equipamento }\end{array}$} & \multicolumn{2}{|c|}{$\begin{array}{l}7 \% \text { sem condições e/ou } \\
\text { sem internet/equipamento }\end{array}$} \\
\hline
\end{tabular}

Os dados do Quadro 1 mostram que quase a totalidade dos estudantes está respeitando o isolamento social de forma integral ou parcial, mas cerca de $80 \%$ têm sentido impactos de ordem financeira ou emocional. Sobre o acesso à internet, cerca de $6 \%$ apresentam limitações ou impedimentos de acesso à internet e cerca de $22 \%$ não possuem computador próprio. Por fim, $84 \%$ indicam que estão aptos para o ensino remoto e os demais não se sentem em condições e/ou não possuem recursos para tal. Os dados indicam que a maior parte dos estudantes possui os recursos necessários e está em condições de acompanhar o ensino não presencial, e foram determinantes para definir que a adesão dos estudantes às atividades remotas será facultativa e também para a abertura de um edital de Apoio à Inclusão Digital, por meio do qual os estudantes podem pleitear recursos para a aquisição de computadores e obter e chips com acesso a pacote de dados de internet.

Quanto aos docentes, o quadro docente é formado por 1.262 professores efetivos, 80 substitutos e mais um conjunto de 300 professores seniores, voluntários, visitantes ou pósdoutorandos que podem atuar na docência. Responderam a consulta 83,9\% dos professores efetivos, 55,8\% dos substitutos e apenas 4,3\% dos demais citados. O Quadro 2 apresenta uma síntese das principais informações fornecidas por este coletivo.

Quadro 2 - Resultados da consulta aos docentes acerca da oferta de atividades curriculares por meios virtuais

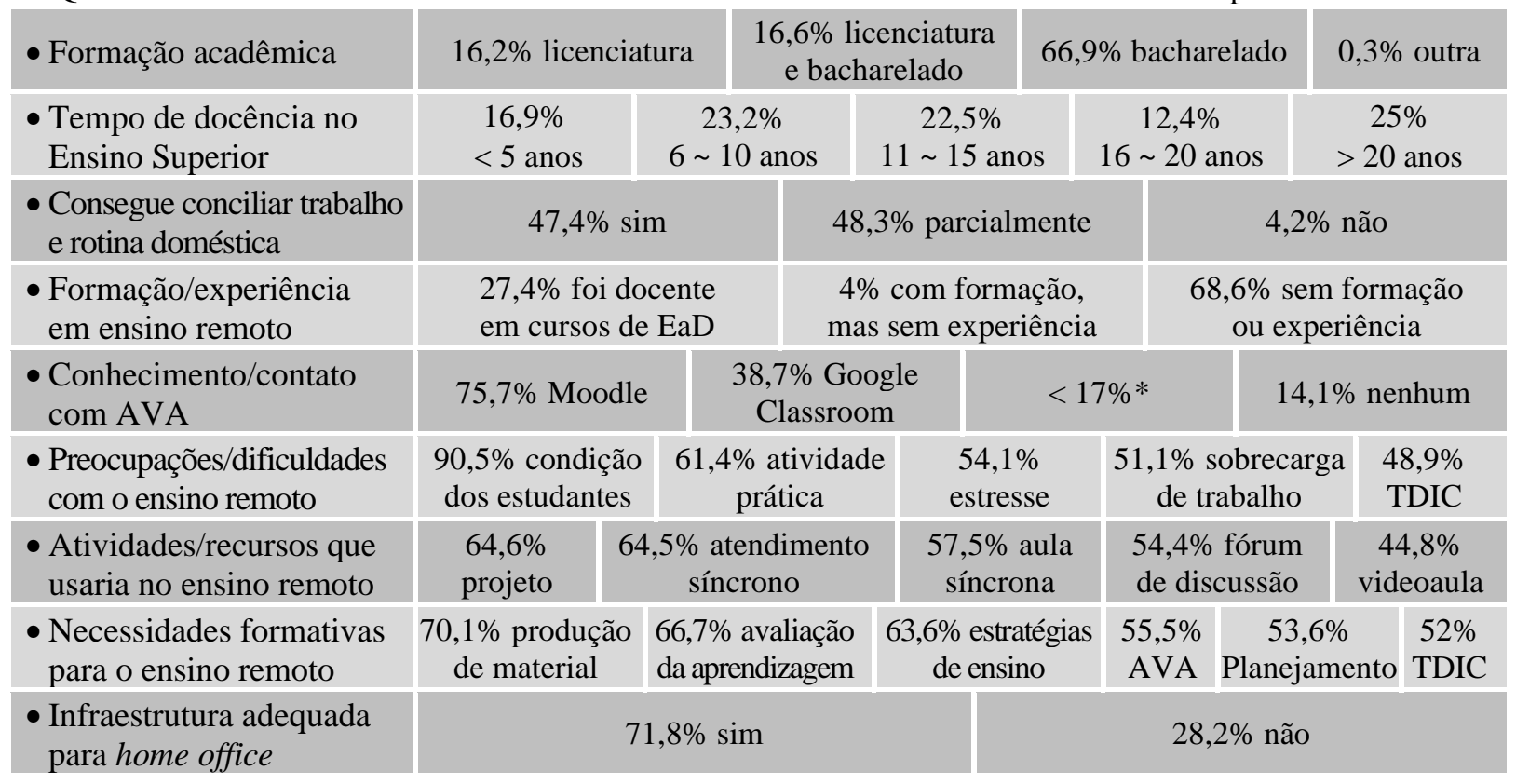

*16,3\% Coursera, 11,6\% Khan Academy. 8,3\% Udemy, 5,5\% Portal Educação, 3,9\% Veduca, 8,7\% outros.

Fonte: UFSCar/ProGrad (2020b) 
A análise dos dados do Quadro 2 mostra que cerca de $33 \%$ dos professores possui formação em licenciatura e quase $60 \%$ têm mais de 10 anos de experiência na atividade docente. Cerca de $96 \%$ estão conseguindo conciliar as atividades de trabalho remoto com a rotina doméstica, mas quase $69 \%$ não possuem formação ou experiência em ensino remoto. Sobre as plataformas institucionais de AVA, 75,7\% conhecem o Moodle e 38,7\%, o Google Classroom. Em relação a preocupações e/ou dificuldades com o ensino remoto, destaca-se com $90,5 \%$ a preocupação com os estudantes. Os professores indicam que no ensino remoto priorizariam as atividades síncronas, mas que necessitam de formação diversificada para ampliar seu repertório pedagógico. Por fim, aproximadamente $72 \%$ indicam que possuem infraestrutura adequada para o trabalho em home office neste período. Embora a maioria dos docentes não possua formação e/ou experiência para atuação no ensino remoto, as respostas indicam que a maioria possui algum conhecimento sobre recursos digitais e estratégias que podem ser adotadas.

O quadro persistente de pandemia no país levou a UFSCar a suspender as atividades presenciais até janeiro de 2021 e, com base nas informações das consultas realizadas, e nos resultados das discussões realizadas no âmbito dos Departamentos Acadêmicos, um Grupo de Trabalho, formado por representantes das categorias de professores, técnico-administrativos e estudantes de todos os oito Centros Acadêmicos dos quatro campi da instituição, elaborou uma proposta de retomada das atividades de graduação de forma não presencial,.

A proposta, amplamente debatida e refinada, foi aprovada pelo Conselho de Graduação e pelo Conselho Universitário da UFSCar. De um modo geral, a proposta recomenda que as atividades acadêmicas indicadas pelas coordenações de curso ocorram de forma remota, em uma modalidade denominada ensino não presencial emergencial (ENPE). Preocupações diversas foram contempladas na proposta, tais como:

- Inclusão digital dos estudantes sem computadores e internet;

- Assinatura de uma biblioteca digital;

- Acessibilidade aos estudantes com deficiência;

- Flexibilização de normas acadêmicas;

- Assessoria pedagógica e tecnológica aos docentes;

- Planejamento pedagógico no âmbito dos Núcleos Docentes Estruturantes (NDE);

- Estrutura de apoio de tutores e monitores.

\section{A TUTORIA PAAEG NO ENSINO NÃO PRESENCIAL EMERGENCIAL}

Considerando a adoção do ENPE na UFSCar, a tutoria PAAEG será fundamental no apoio acadêmico ao estudante de graduação. Para proceder com a adequação das atividades da tutoria PAAEG em atendimentos não presenciais foi realizada uma consulta preliminar na qual 92\% dos tutores inicialmente selecionados indicaram que permanecerão no programa nas condições de atendimento não presencial. Em seguida, procedeu-se uma consulta sobre as condições gerais dos tutores selecionados, por meio de formulário on-line, com o objetivo de fazer um diagnóstico sobre as principais dificuldades e possibilidades de atuação dos tutores no formato remoto e uma síntese das informações é apresentada no Quadro 3.

Considerando que as atividades acadêmicas ofertadas remotamente foram indicadas pelas coordenações de curso e negociadas com os departamentos ofertantes, houve alterações nas demandas previstas anteriormente para o ensino presencial e agora implantadas no ENPE, mas aproximadamente $86 \%$ dos tutores consideram haver a possibilidade de atender outra disciplina/área. Todos os tutores possuem algum tipo de dispositivo ou equipamento e com acesso à internet, sendo 94,4\% de uso individual e 5,6\% de uso coletivo. Computadores e 
smartphones foram apontados como os principais equipamentos disponíveis, constituindo 94,4 e $87,3 \%$, respectivamente. Todos os tutores também informaram possuir algum tipo de acesso à internet, sendo que o principal é o wifi $(81,7 \%)$, seguido de internet a cabo ou fibra ótica $(47,9 \%)$. Cerca de $24 \%$ possui acesso à internet com limite de dados, mas esse problema está sendo resolvido institucionalmente.

Quadro 3 - Resultados da consulta aos estudantes tutores selecionados em 2020

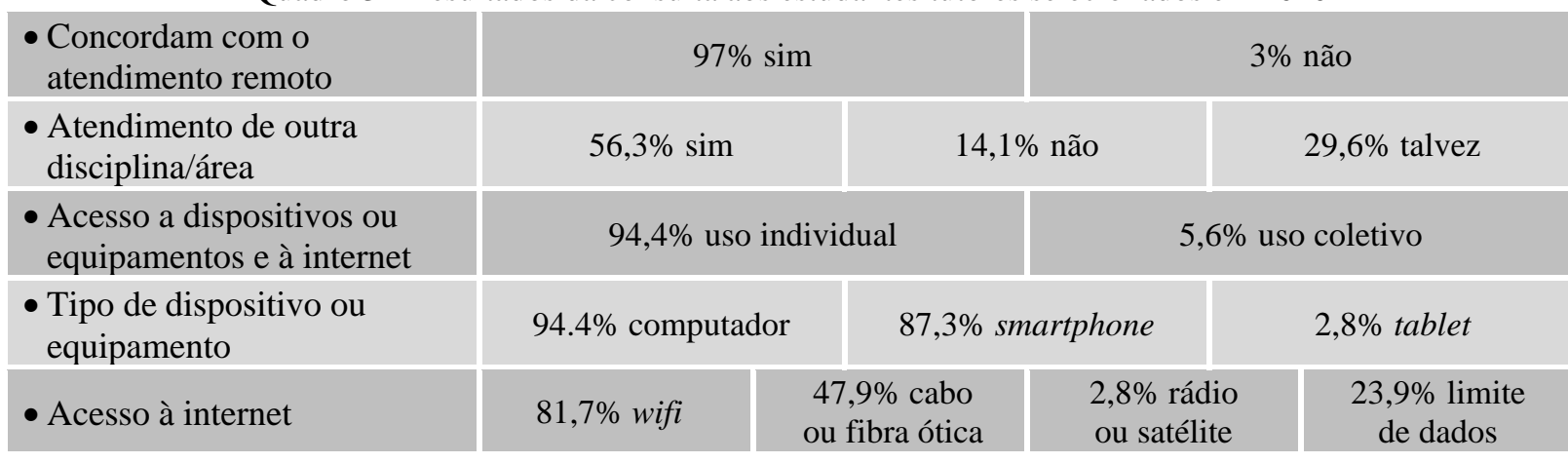

Fonte: Autoria própria

De posse destas informações e assumindo a premissa de garantia das bolsas durante todo o período de duração do calendário do ENPE, passou-se a analisar a essência da tutoria PAAEG para garanti-la e estruturá-la no atendimento não presencial. Um novo evento de capacitação dos tutores foi realizado, agora em formato on-line, em tempo hábil para que os atendimentos fossem iniciados logo após o início das aulas. Neste evento, foi apresentada e discutida a nova proposta de trabalho, bem como foram apresentados recursos digitais que poderão ser utilizados como instrumentos de apoio à tutoria on-line, como o Google Jamboard e até a "técnica da mãozinha" que consiste em utilizar a câmera do smartphone conectado ao computador para transmitir explicações escritas à mão em papel.

Para garantir um único local onde os atendimentos serão realizados foi estruturada uma sala virtual no Ambiente Virtual Administrativo (AVAdmin) na qual são disponibilizadas informações sobre todas as áreas/disciplinas atendidas nos diferentes campi, tipos de tutoria, tutores responsáveis, horários de atendimento e links de acesso à plataforma Google Meet para os atendimentos.

$\mathrm{O}$ atendimento no Google Meet busca auxiliar os estudantes atendidos a desenvolverem uma rotina apropriada de estudos e incentivá-los a buscar processos de aprendizagem com mais autonomia, mantendo-se o objetivo principal da tutoria. A organização dos estudos no formato de ENPE passou a ser mais uma orientação que os tutores darão aos estudantes atendidos. Os tutores utilizarão os equipamentos que tiverem disponíveis e os aplicativos que se mostrarem adequados para cada área específica. Além disso, continuarão ofertando $6 \mathrm{~h}$ de atendimentos nas duas modalidades, porém com algumas adequações:

- Tutoria de acompanhamento - o tutor se reunirá semanalmente com um grupo fixo de até 8 estudantes previamente inscritos; o acompanhando dos estudos em uma atividade curricular específica desses alunos ocorrerá ao longo de duas horas; o grupo fixo permitirá ao tutor um planejamento prévio da próxima sessão de estudos;

- Tutoria livre - o tutor receberá qualquer estudante para uma sessão assistida de forma similar à monitoria, mas mantendo o diferencial de propor que o aluno atendido estude e busque soluções para suas dúvidas de forma ativa. 


\section{CONSIDERAÇÕES FINAIS}

O programa de tutoria PAAEG foi criado em 2017 na UFSCar e tem como objetivo principal desenvolver nos estudantes hábitos de estudo mais frequentes, produtivos e autônomos. O foco do programa são os estudantes ingressantes e as disciplinas com elevados índices de retenção, buscando desta forma, combater indiretamente a evasão dos estudantes.

As modalidades principais de atendimento da tutoria são: tutoria de acompanhamento e tutoria livre, nas quais estudantes tutores buscam proporcionar uma contribuição diferenciada das tradicionais monitorias que funcionam basicamente para tirar dúvidas pontuais. Os relatos dos estudantes e tutores participantes indicam que o programa tem contribuído na formação global de todos, mas em 2020, como consequência da pandemia de COVID-19, houve a necessidade de se adaptar rapidamente ao novo formato de ensino não presencial emergencial. Novas estratégias de atendimento da tutoria usando TDICs foram delineadas, considerando inclusive contribuições dos próprios estudantes tutores.

O formato não presencial de atendimento da tutoria PAAEG foi implantado com sucesso e questionários on-line de avaliação das atividades da tutoria e de sua efetiva contribuição para o aprimoramento das estratégias de estudo e aprendizagem serão encaminhadas ao final do período letivo. A expectativa dos proponentes é que a tutoria PAAEG possa atingir seus objetivos, mesmo com este novo cenário atípico e imprevisível, mas que propiciou momentos de reflexão, planejamento e ação na busca por soluções criativas baseadas no uso de tecnologias diversificadas na educação. A certeza é que todos nós estamos aprendendo muito com todo esse processo e talvez seja impossível retroceder totalmente aos modelos presenciais convencionais de ensino e de tutoria.

\section{REFERÊNCIAS}

ANDRETO, M. N. Um estudo de caso sobre evasão na UFSCar. 2015. 78 p. Trabalho de Conclusão de Curso (Graduação em Estatística) - Universidade Federal de São Carlos, São Carlos, 2015.

BURDE, D. et al. Education in Emergencies: A Review of Theory and Research, Review of Educational Research, v. 87, n. 3, p 619-658, 2017.

DALBELO, T. M.; REZENDE, A. C. ACIEPE Matemática Elementar: um passo para a adaptação de disciplinas presenciais em disciplinas remotas. In: V Congresso Internacional de Educação e Tecnologias/Encontro de Pesquisadores em Educação a Distância (CIET:EnPED), 2020, São Carlos. Anais. São Carlos, 2020..

HODGES, C. et al. The Difference Between Emergency Remote Teaching and Online Learning. EDUCAUSE Review. 27 mar. 2020.

ICMC. Um guia para sobreviver à pandemia do ensino remoto. Portal USP São Carlos, São Carlos, 7 maio 2020. Disponível em: http://www.saocarlos.usp.br/um-guia-para-sobreviver-apandemia-do-ensino-remoto/. Acesso em: 4 jun. 2020.

\section{INSTITUTO NACIONAL DE ESTUDOS E PESQUISAS EDUCACIONAIS ANÍSIO TEIXEIRA. Sinopse Estatística da Educação Superior 2015. Brasília: Inep, 2016.}

LOBO, M. B. C. M. Panorama da Evasão no Ensino Superior Brasileiro: Aspectos Gerais das Causas e Soluções. Associação Brasileira de Mantenedoras de Ensino Superior. Cadernos, n. 25, dez. 2012. 
"Os desafios para formar hoje o engenheiro do amanhã"

MOUSSA, C. B. G. et al. O programa de tutoria da UFSCar: acolhimento e apoio acadêmico ao estudante de graduação. In: IV Congresso de Ensino de Graduação da UFSCar, 2019, São Carlos. Anais. São Carlos, 2019.

PASSOS, F. J. V. et al. Programa de Tutoria: uma esperança. In: XXIX Congresso Brasileiro de Ensino de Engenharia, 2001, Porto Alegre. Anais. Porto Alegre: PUCRS, 2001a.

PASSOS, F. J. V. et al. Programa de Tutoria: uma experiência. In: XXIX Congresso

Brasileiro de Ensino de Engenharia, 2001, Porto Alegre. Anais. Porto Alegre: PUCRS, 2001b.

SINCLAIR, M. Education in Emergencies. In: CRISP, J. TALBOT, C.; CIPOLLONE, D. B. (ed.). Learning for a Future: Refugee Education in Developing Countries. Geneva: United Nations High Commissioner for Refugees (UNHCR), 2001, p. 1-84.

UNIVERSIDADE FEDERAL DE SÃO CARLOS. Pró-Reitoria de Graduação. Consulta aos discentes acerca de suas condições de acesso ao ensino por meios virtuais. São Carlos 2020a. Disponível em: http://www.prograd.ufscar.br/FormulariodiscenteFase2ATUALIZADO.pdf. Acesso em: 20 jul. 2020.

UNIVERSIDADE FEDERAL DE SÃO CARLOS. Pró-Reitoria de Graduação. Consulta aos docentes acerca da oferta de atividades curriculares por meios virtuais. São Carlos, 2020b. Disponível em: http://www.prograd.ufscar.br/Formulariodocente_julho2020.pdf. Acesso em: 20 jul. 2020.

WATANABE, F. Y. et al. Formação docente me metodologias ativas e o uso de tecnologias digitais de informação e comunicação (TDIC) no ensino remoto emergencial. In: V Congresso Internacional de Educação e Tecnologias/Encontro de Pesquisadores em Educação a Distância (CIET:EnPED), 2020, São Carlos. Anais. São Carlos, 2020.

\title{
THE TUTORING PROGRAM IN THE EMERGENCY REMOTE UNDERGRADUATE TEACHING AT THE FEDERAL UNIVERSITY OF SÃO CARLOS
}

\begin{abstract}
The high retention rate in initial curricular activities in undergraduate courses is one of the causes of student dropout and the cause for concern by Higher Education Institutions (HEIs). Freshman students need to adapt quickly to new academic routines and a new teaching-learning model that requires more autonomy and discipline in their studies. Seeking to offer academic support to incoming students, the Federal University of São Carlos (UFSCar) structured in 2017 a tutoring program in which tutor students assist other students to develop an appropriate study routine, aiming at a possible improvement in performance throughout their course. The growth in the number of visits over the years and the reports of the students which are attended indicate that the tutoring program has contributed globally to their formation. However, in 2020, as a reflection of the COVID-19 pandemic, all undergraduate education changed to remote format and the tutoring program had to adapt to this new context. Using Digital Information and Communication Technologies (DICTs) available to tutor students and students attended, and also a certain amount of creativity, remote strategies were defined in order to preserve the guiding principles of the program that aim to encourage students to create a study routine and search for more efficient ways of studying and learning. In this work, it is reported the process of creating and implementing the UFSCar tutoring program, as well as its adequacy to the remote modality.
\end{abstract}

Keywords: Emergency Remote Teaching. Online Learning. DICT. Student dropout. 